University of Windsor

Scholarship at UWindsor

$6-11-2011$

\title{
C02 Production in the Bromate-1,4-Cyclohexanedione Oscillatory Reaction
}

Jiamin Feng

University of Windsor

James R. Green

University of Windsor

Samuel A. Johnson

University of Windsor

Jichang Wang

University of Windsor

Follow this and additional works at: https://scholar.uwindsor.ca/chemistrybiochemistrypub

Part of the Biochemistry, Biophysics, and Structural Biology Commons, and the Chemistry Commons

\section{Recommended Citation}

Feng, Jiamin; Green, James R.; Johnson, Samuel A.; and Wang, Jichang. (2011). CO2 Production in the Bromate-1,4-Cyclohexanedione Oscillatory Reaction. Journal of Physical Organic Chemistry, 24 (6), 507-512.

https://scholar.uwindsor.ca/chemistrybiochemistrypub/74

This Article is brought to you for free and open access by the Department of Chemistry and Biochemistry at Scholarship at UWindsor. It has been accepted for inclusion in Chemistry and Biochemistry Publications by an authorized administrator of Scholarship at UWindsor. For more information, please contact scholarship@uwindsor.ca. 


\title{
$\mathrm{CO}_{2}$ production in the bromate-1,4-cyclohexanedione oscillatory reaction
}

\author{
Jiamin Feng ${ }^{a}$, James R. Green ${ }^{a *}$, Samuel A Johnson ${ }^{a}$ and Jichang Wang ${ }^{a *}$
}

\begin{abstract}
NMR and GC/MS spectroscopy of the organic extracts of the oscillatory bromate-1,4-cyclohexanedione reaction illustrate the presence of ring-opening products 5-(dibromomethylene)-2(5H)-furanone, (E)-5,5,5-tribromo-4-oxo-2pentenoic acid, and dibromoacetic acid, particularly at elevated temperatures. The loss of a carbon atom from the six-membered ring after ring opening led to gas formation and such a process became more vigorous at $>60^{\circ} \mathrm{C}$, with the direct observation of bubbles in a stirred batch reactor. Gravimetric experiments confirm that the amount of carbon dioxide gas produced increases rapidly with reaction temperature. Parallel experiments suggest that the ring-opening process involves the oxidation of brominated benzoquinones by bromate. Copyright () 2010 John Wiley \& Sons, Ltd.
\end{abstract}

Supporting information may be found in the online version of this paper.

Keywords: oscillatory reaction; reaction mechanism; spectroscopy

\section{INTRODUCTION}

The bromate-based oscillations, originally discovered with malonic acid, are now more regularly studied on more robust systems such as pyrocatechol and particularly 1,4-cyclohexanedione(CHD). ${ }^{[1-15]}$ While in most of the bromate-cyclic compound oscillators the oscillatory behavior is short-lived when studied in a batch system, ${ }^{[1,2]}$ over 200 oscillation peaks have been achieved in the closed bromate-1,4-cyclohexanedione $(\mathrm{CHD}){ }^{[3]}$ The long lasting oscillatory dynamics, coupled with the absence of gas production, has made the bromate-CHD reaction a new popular model system for the investigation of nonlinear spatial-temporal dynamics, ${ }^{[13-15]}$ an important behavior that has been encountered in a variety of systems ranging from physical to biological systems. ${ }^{[16-20]}$ The understanding of the chemical mechanism of the bromate-CHD oscillator has achieved significant progress largely due to the work by Körös and his research group. Models proposed by Szalai and co-workers have successfully reproduced temporal oscillatory behavior seen in both the catalyzed and uncatalyzed bromate-CHD reactions. ${ }^{[9]}$ Despite the great success in reproducing those temporal oscillations, wave behavior observed in the catalyzed bromate-CHD system, in particular the anomalous wave dispersion relationship cannot be reproduced with the existing model. ${ }^{[14,15]}$ Therefore, further mechanistic investigation is desired for the further application of this new model system.

This research was particularly motivated by a brief note in a recent study of high frequency oscillations in the chemical oscillator, which stated the observation of gas bubbles in the bromate-CHD reaction at high reaction temperature. ${ }^{[21]}$ Very recently, we observed gas production in the bromate-pyrocatechol reaction and determined the presence of a ring-opening process with mass spectroscopic, NMR spectral, and crystallographic studies. ${ }^{[22]}$ Considering the similarity of pyrocatechol and CHD in their molecular structures, we become curious on whether a ring-opening reaction and thus carbon dioxide production also exists in the bromate-CHD reaction. In complement to the earlier mechanistic investigation on the CHD system, ${ }^{[9]}$ this study focuses on the occurrence of ring-opening reactions as it is important for future experimental work and is helpful for understanding the underlying mechanism. As shown below, a ring opening product, 5-dibromomethylene-2(5H)-furanone (1) was detected over a broad range of reaction temperatures, and ring opening products dibromoacetic acid and (E)-5,5,5-tribromo-4-oxo-2-pentenoic acid (2) were detected at temperatures $\geq 60{ }^{\circ} \mathrm{C}$, suggesting that gas was produced during the oxidation process and thus providing an explanation to the earlier puzzling experimental observation. ${ }^{[21]}$

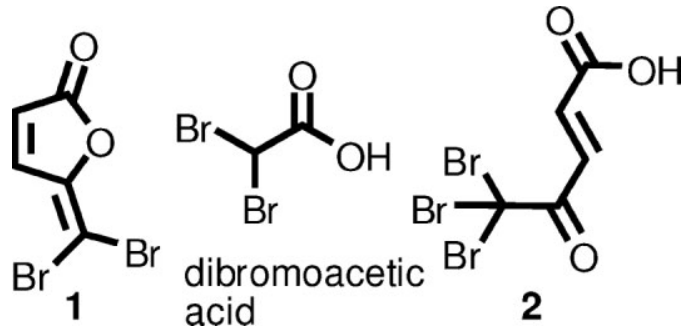

* Correspondence to: J. R. Green and J. Wang, Department of Chemistry and Biochemistry, University of Windsor, Ontario N9B 3P4, Canada.

E-mail: jgreen@uwindsor.ca; E-mail: jwang@uwindsor.ca

a J. Feng, J. R. Green, S. A Johnson, J. Wang

Department of Chemistry and Biochemistry, University of Windsor, Ontario N9B 3P4, Canada 


\section{EXPERIMENTAL SECTION}

All reactions were carried out in a thermal-jacketed $50 \mathrm{ml}$ glass beaker (ChemGlass). The reaction temperature was kept constant at a preselected value $\left( \pm 0.1^{\circ} \mathrm{C}\right)$ through a circulating water bath (Thermo NesLab RTE 7). A Teflon cap was placed on the top of the reactor to hold the electrodes. The reaction solution was stirred with a magnetic stirring bar driven by a magnetic stirrer (Fisher Isotemp). Reactions were monitored with a platinum electrode against a $\mathrm{Hg} / \mathrm{Hg}_{2} \mathrm{SO}_{4} / \mathrm{K}_{2} \mathrm{SO}_{4}$ reference electrode filled with saturated $\mathrm{K}_{2} \mathrm{SO}_{4}$ solution (Radiometer Analytical, XR200). All measurements were recorded through a $\mathrm{pH} /$ potential meter (Radiometer PHM220) connected to a personal computer through a PowerLab/4SP data logger.

All ${ }^{1} \mathrm{H}$ NMR and ${ }^{13} \mathrm{C}$ NMR measurements were carried out using Bruker Avance 500 and 300 spectrometers, and with the same sample that was used for the gas chromatography-mass spectrometry (GC/MS) study. NMR samples were dissolved in chloroform-d (99.8\%), purchased from Aldrich. GC/MS was performed on a Varian CP-3800/Varian 1200L system, using a $15 \mathrm{~m}$ Varian CP-Sil $5 \mathrm{CB}$ column. Stock solutions of $\mathrm{NaBrO}_{3}$ (Aldrich, 99\%), 1.2 M, and sulfuric acid (Aldrich, 95-98\%), 6.0 M, were prepared with double-distilled water. Ferroin, $0.025 \mathrm{M}$, was prepared from a calculated amount of $\mathrm{FeSO}_{4} \bullet 7 \mathrm{H}_{2} \mathrm{O}$ (Aldrich, $99+\%)$ and 1,10-phenanthroline (Aldrich, 99+\%). CHD (Aldrich, $98 \%)$ was directly dissolved in the reaction mixture. The volume of the reaction mixture was fixed at $30.0 \mathrm{ml}$ in all experiments.

\section{RESULTS AND DISCUSSION}

The analysis of the products of the bromate-CHD reaction has been performed under various reaction conditions. Figure 1 presents four typical time series of the uncatalyzed (Figs. 1a and c) and ferroin-catalyzed (Figs. $1 \mathrm{~b}$ and d) bromate-CHD systems at different reaction temperatures, which was $25^{\circ} \mathrm{C}$ in Figs. 1 (a) and (b), and $40^{\circ} \mathrm{C}$ in Figs. 1(c) and (d). Other initial conditions were $[\mathrm{CHD}]=0.03 \mathrm{M},\left[\mathrm{NaBrO}_{3}\right]=0.1 \mathrm{M}$, and $\left[\mathrm{H}_{2} \mathrm{SO}_{4}\right]=1.0 \mathrm{M}$. The concentration of ferroin was $1 \mathrm{mM}$ in Figs. 1(b) and (d). Spontaneous oscillations emerged and stopped at ca. 170 and $260 \mathrm{~min}$, respectively in Fig. 1(a). When $1 \mathrm{mM}$ ferroin was added in Fig. 1(b), both the starting and ending time of the oscillations were advanced. Meanwhile, the duration of the oscillatory process became longer. When the temperature was increased to $40{ }^{\circ} \mathrm{C}$ in Figs. $1(\mathrm{c})$ and (d), as expected, the oscillatory window finished in a shorter time both in the absence (Fig. 1c) and presence (Fig. 1d) of ferroin. When the temperature was increased further to above $70^{\circ} \mathrm{C}$, no spontaneous oscillations could be achieved.

To carry out the analysis, reaction solutions were extracted by diethyl ether just before or after the oscillatory window, labeled respectively as I and II in Fig. 1. Extracted solutions of the above reactions were analyzed by NMR and GC/MS spectroscopy. Figure 2 presents the ${ }^{1} \mathrm{H}$ NMR spectrum recorded in the $\mathrm{CDCl}_{3}$ solution obtained from the reaction presented in Fig. 1(c). In Fig. 2(a), the solution was extracted just before the beginning of these spontaneous oscillations. A ${ }^{1} \mathrm{H}$ NMR spectral resonance appearing at $\delta 6.73$ was observed, corresponding to the intermediate 1,4-hydroquinone $(\mathrm{HQ})$; this intermediate was further confirmed by the ${ }^{13} \mathrm{C}$ NMR resonances appearing at 116.2 and $154.0 \mathrm{ppm}$ in the most concentrated samples. $\mathrm{A}^{1} \mathrm{H}$ NMR resonance at $\delta 6.80$, attributable to 1,4-benzoquinone (BQ),
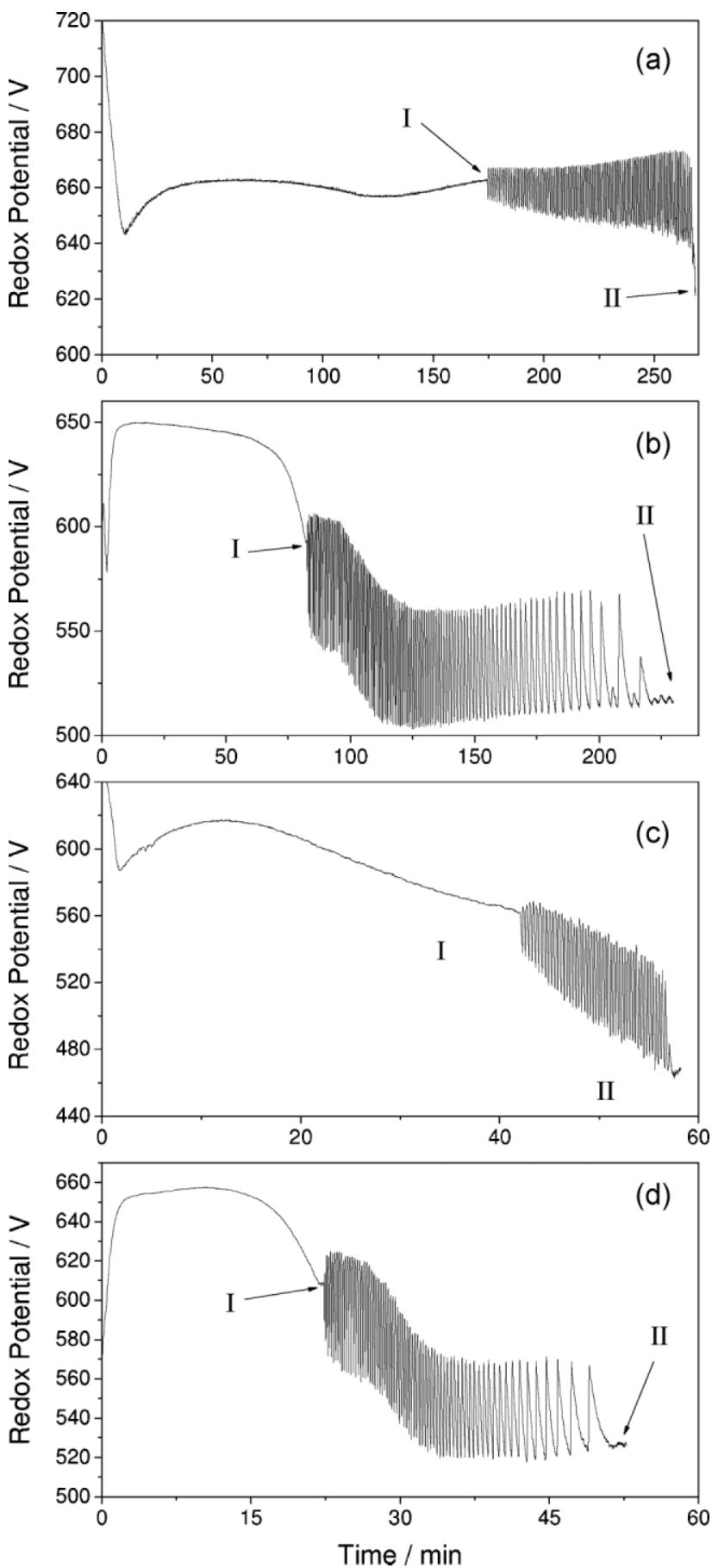

Figure 1. Time series collected in the oscillatory bromate-CHD reaction. The temperature is $25^{\circ} \mathrm{C}$ in (a) and (b) and $40^{\circ} \mathrm{C}$ in (c) and (d). The composition of the solution is $0.03 \mathrm{M} \mathrm{CHD}, 0.10 \mathrm{M} \mathrm{NaBrO}$, and $1.0 \mathrm{M}$ $\mathrm{H}_{2} \mathrm{SO}_{4} .1 .0 \mathrm{mM}$ ferroin was present in (b) and (d)

was also found in smaller amounts; this was further supported by the ${ }^{13} \mathrm{C}$ NMR spectral resonances at 135.6 and $187.2 \mathrm{ppm}$ in more highly concentrated samples. In addition, 2-bromo1,4-hydroquinone (BrHQ) [ ${ }^{1} \mathrm{H}$ NMR $\delta=6.99,(\mathrm{~d}, J=2.8 \mathrm{~Hz}) ; 6.90(\mathrm{~d}$, $J=8.8 \mathrm{~Hz}) ; 6.73(\mathrm{dd}, J=8.8,2.8 \mathrm{~Hz})]$ could also be detected in the solution. At the end of the oscillations, as illustrated in Fig. 2(b), 1,4-benzoquinone and 2-bromo-1,4-benzoquinone (BrBQ) $[\delta=7.31(\mathrm{~d}, J=2.4 \mathrm{~Hz}) ; 6.97(\mathrm{~d}, J=10.0 \mathrm{~Hz}) ; 6.83(\mathrm{dd}, J=10.0$, $2.4 \mathrm{~Hz})$ ) were present in significant amounts, at the expense of 

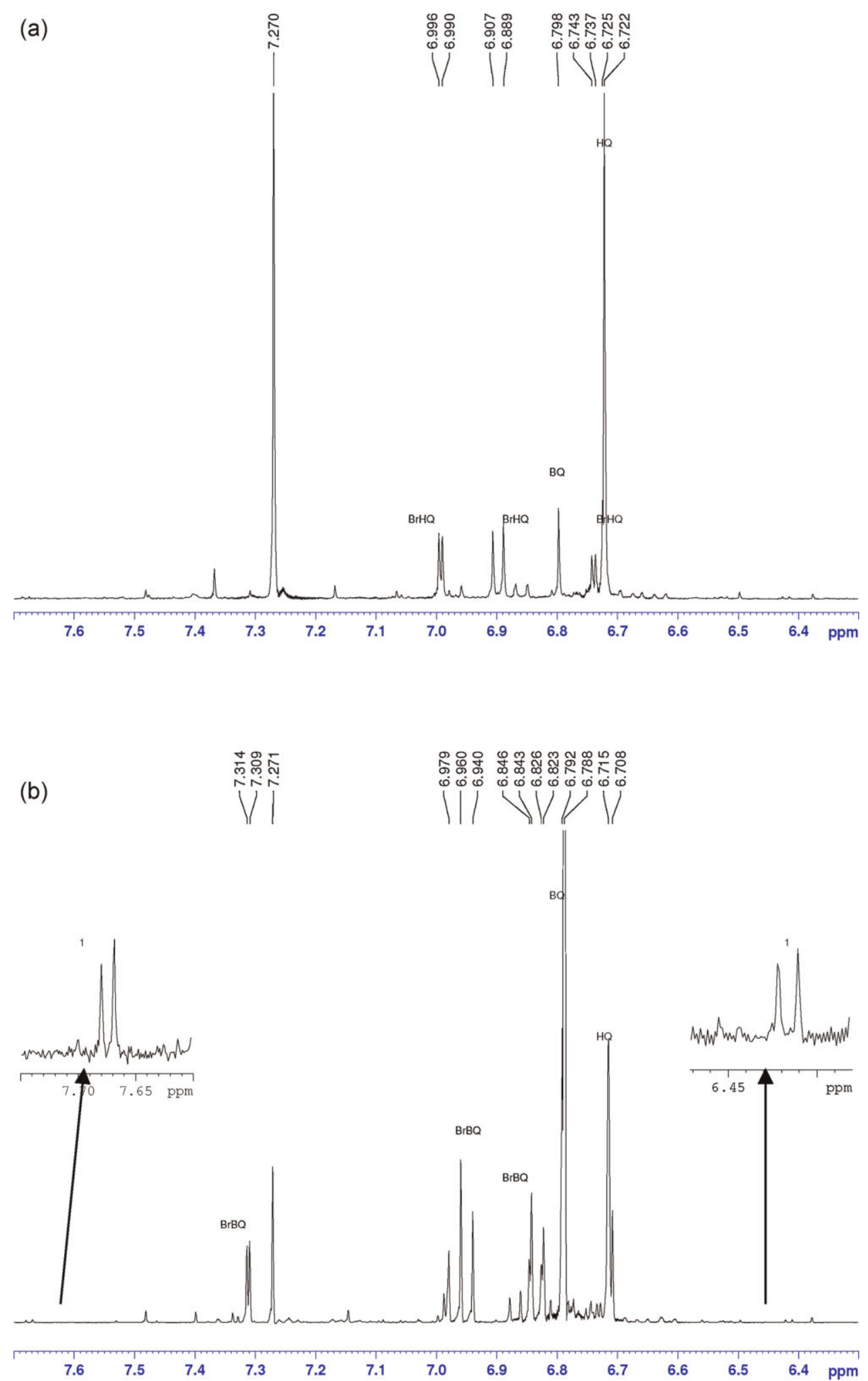

Figure 2. ${ }^{1} \mathrm{H}$ NMR $(500 \mathrm{MHz})$ spectra of the product solutions obtained before (a) and after (b) the oscillation. The other reaction conditions are $[\mathrm{CHD}]=0.03 \mathrm{M},\left[\mathrm{NaBrO}_{3}\right]=0.10 \mathrm{M},\left[\mathrm{H}_{2} \mathrm{SO}_{4}\right]=1.0 \mathrm{M}$, and $T=40^{\circ} \mathrm{C}$. Key: $\mathrm{HQ}=$ Hydroquinone, $\mathrm{BQ}=1,4$-benzoquinone, BrHQ $=2$-bromo-1,4-hydroquinone, $\mathrm{BrBQ}=2$-bromo-1,4-benzoquinone, and $\mathbf{1}=5$-dibromomethylene-2(5H)-furanone

1,4-hydroquinone and 2-bromo-1,4-hydroquinone. In addition, a pair of ${ }^{1} \mathrm{H}$ NMR spectral resonances could be observed at $\delta 7.68(\mathrm{~d}$, $J=5.6 \mathrm{~Hz})$ and $6.42(\mathrm{~d}, J=5.6 \mathrm{~Hz})$, respectively, which have been assigned conclusively to 5-dibromomethylene-2(5H)-furanone
(1) ${ }^{22}$ this compound almost invariably appeared after oscillation was complete. As only five carbon atoms are included in its molecular structure and it can only be created from 1,4-cyclohexanedione or its oxidation intermediate, carbon 
dioxide is likely to have been produced in the oxidation reaction. At $25-40{ }^{\circ} \mathrm{C}$, however, this compound was only a minor constituent of the reaction mixture, representing (by ${ }^{1} \mathrm{H}$ NMR spectral integration) only ca. $1 \%$ of the dominant post-oscillation product (BQ). In contrast, at $90^{\circ} \mathrm{C}$, although benzoquinone and 2-bromo-1,4-benzoquinone were still present after $90 \mathrm{~min}$, 5-dibromomethylene-2(5H)-furanone (1) had been formed in approximately three times the amount of remaining benzoquinone (see supplementary document). In addition, a significant amount of a material (approximately three times the amount of benzoquinone) assigned as dibromoacetic acid ( $\delta=5.85$ in the ${ }^{1} \mathrm{H}$ NMR spectrum) was observed. The final major component of the reaction mixture, and the most abundant compound of all (approximately six to seven times the amount of benzoquinone), gave ${ }^{1} \mathrm{H}$ NMR spectral resonances at $\delta=8.01(\mathrm{~d}, J=15.4 \mathrm{~Hz})$ and $\delta=7.14(\mathrm{~d}, J=15.4 \mathrm{~Hz})$ (see supplementary document). This compound could be isolated by crystallization from hexanes, and gave an MS (direct insertion mode $m / e$ 99, $\mathrm{M}^{+}-\mathrm{CBr}_{3}$ ), an IR spectrum featuring $v_{\max }$ of 3000 and $1696 \mathrm{~cm}^{-1}$, and a ${ }^{13} \mathrm{C} \mathrm{NMR}$ spectrum containing resonances at $\delta$ 178.5, 168.0, 135.2, 131.9, and 42.7. X-ray crystallographic analysis confirmed the structure of this compound to be (E)-5,5,5-tribromo-4-oxo-2-pentenoic acid (2) (Fig. 3). The formation of both dibromoacetic acid and (E)-5,5,5-tribromo-4-oxo- 2-pentenoic acid also likely require the formation of $\mathrm{CO}_{2}$. This product distribution was essentially identical in catalyzed and non-catalyzed reactions at $90^{\circ} \mathrm{C}$. In a manner consistent with an earlier mechanistic investigation, ${ }^{[10]}$ our experiments show no ring-opening products in the reaction between ferriin and CHD at elevated temperature.

To further confirm the molecular structures of these products, especially the ring-opening species, GC/MS was performed as well. Figure 4(a) presents a typical total ion current (TIC) chromatography. The test solution was prepared at the end of the oscillatory process in the uncatalyzed bromate-CHD reaction performed at $40^{\circ} \mathrm{C}$. Several peaks can be observed in the mass spectrum. The component that eluted at $5.85 \mathrm{~min}$ with a $\mathrm{m} / \mathrm{z}$ of $186 / 188$ corresponds to 2-bromo-1,4-benzoquinone. (Fig. 4a). The peak at $6.40 \mathrm{~min}$ is due to 2-bromo-1,4-hydroquinone $(m / z=188 / 190) \quad$ (Fig. 4c). Dibromo-1,4-hydroquinone can be found with an elution time of $8.32 \mathrm{~min}(\mathrm{~m} / \mathrm{z}=266 / 268 / 270)$ (Fig. 4d). The peak eluting at $9.01 \mathrm{~min}$ (Fig. 4e) contains an $\mathrm{m} / \mathrm{z}$ of 252/254/256, consistent with ring opening product 5-dibromomethylene-2(5H)-furanone (1). The GC/MS of the $90{ }^{\circ} \mathrm{C}$ reaction mixture confirmed the presence of benzoquinone $\left(t_{R}=1.9 \mathrm{~min}, \mathrm{~m} / \mathrm{z}=108\right)$, 2-bromo-1,4-benzoquinone, dibromoacetic acid $\left(t_{R}=7.1 \mathrm{~min}, \quad m / z=216 / 218 / 220\right)$, and 5-dibromomethylene-2(5H)-furanone.

At reaction temperatures between 20 and $40{ }^{\circ} \mathrm{C}$ where the bromate-CHD oscillations have been frequently investigated,

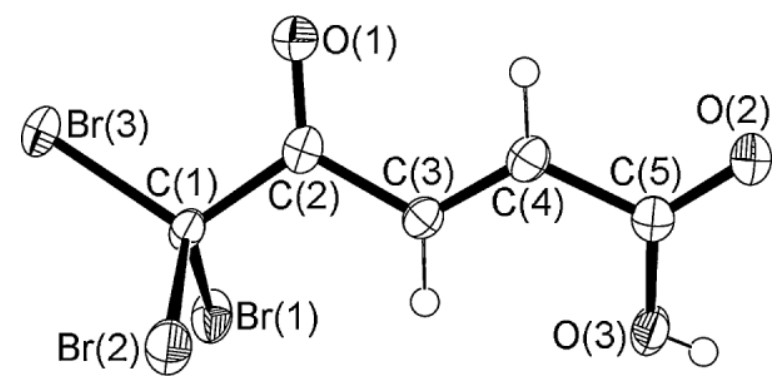

Figure 3. ORTEP representation of X-ray crystallographic structure of (E)-5,5,5-tribromo-4-oxo-2-pentenoic acid (2)
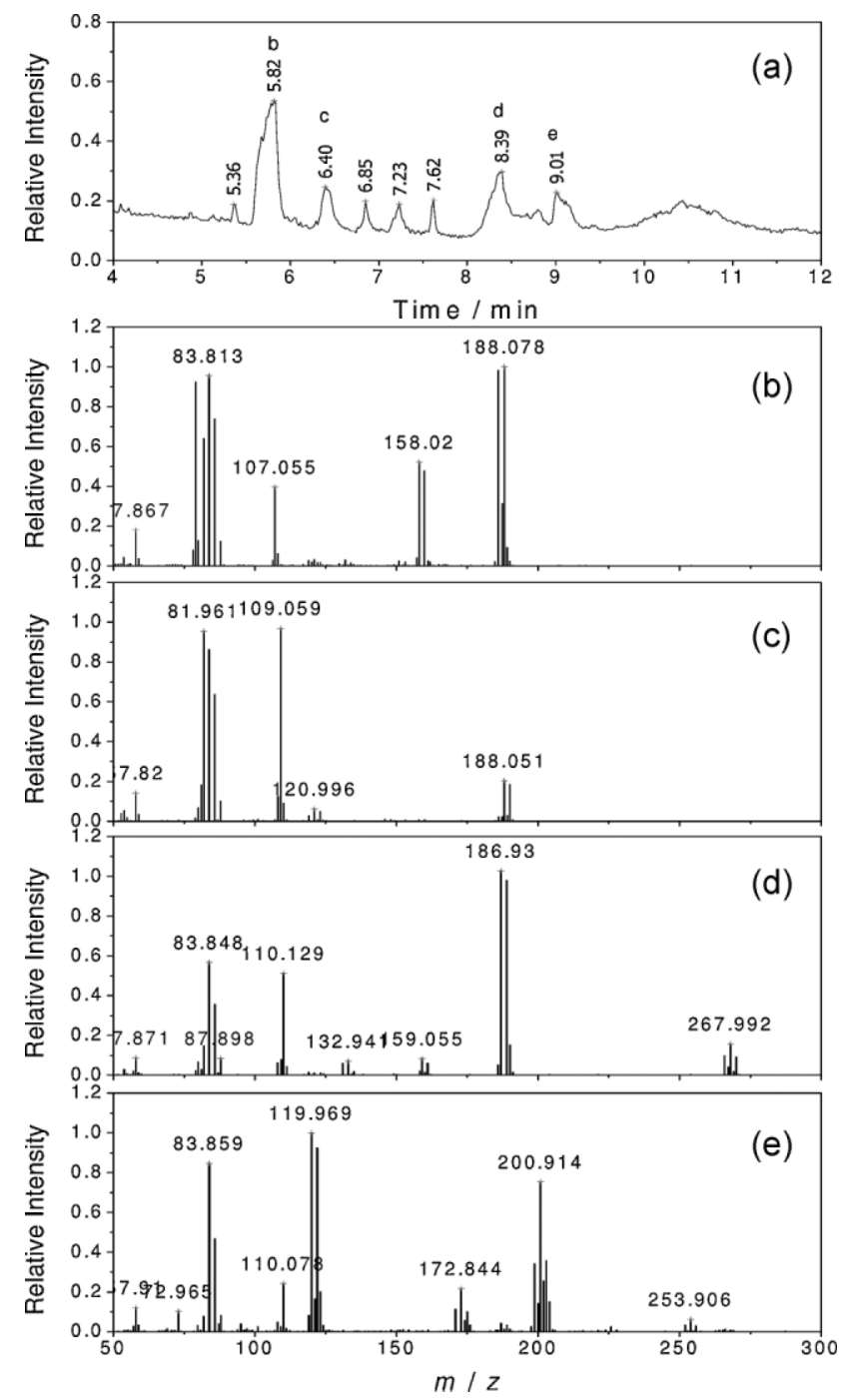

Figure 4. (a) TIC chromatogram of the product solution in Fig. 2(b) and the El mass spectrum corresponding to the component eluting at $5.85 \mathrm{~min}$ (b), $6.40 \mathrm{~min}(\mathrm{c}), 8.32 \mathrm{~min}(\mathrm{~d})$, and $9.01 \mathrm{~min}(\mathrm{e})$

5-dibromomethylene-2(5H)-furanone could only be found, in small amounts, by NMR spectroscopy at the end of the oscillatory window. As one carbon atom is lost from the six-membered ring, $\mathrm{CO}_{2}$ is expected to be generated. To examine the dependence of $\mathrm{CO}_{2}$ production on reaction temperature, the amounts of $\mathrm{CO}_{2}$ were measured by gravimetry, in which the produced $\mathrm{CO}_{2}$ was brought out by nitrogen gas from the enclosed reactor. Contamination by $\mathrm{Br}_{2}$ and $\mathrm{HBr}$ were detected by starch-Nal and acidic $\mathrm{AgNO}_{3}$ solution, respectively. Since $\mathrm{Br}_{2}$ and $\mathrm{HBr}$ may affect the precipitation of $\mathrm{BaCO}_{3}$ through causing a change of the solution $\mathrm{pH}$, the gas flow was scrubbed by a solution containing $0.1 \mathrm{M} \mathrm{H}_{2} \mathrm{SO}_{4}$ and $0.1 \mathrm{M} \mathrm{Nal}$ before it was introduced to the alkaline $\mathrm{BaCl}_{2}$ solution. Figure 5 depicts the amount of $\mathrm{CO}_{2}$ produced under different reaction temperatures, where the yield increases with temperature for both the catalyzed and uncatalyzed bromate-CHD reaction. The amount of CHD used in those experiments was $9 \mathrm{mM}$. It is noted that observable bubbles appeared in the reactor when the temperature was increased to above ca. $60^{\circ} \mathrm{C}$. Epstein et al. also noted that vigorous gas evolution was observed during the oxidation in the solution containing a high concentration of bromate and $\mathrm{CHD}$ at $85{ }^{\circ} \mathrm{C}^{21}$ 


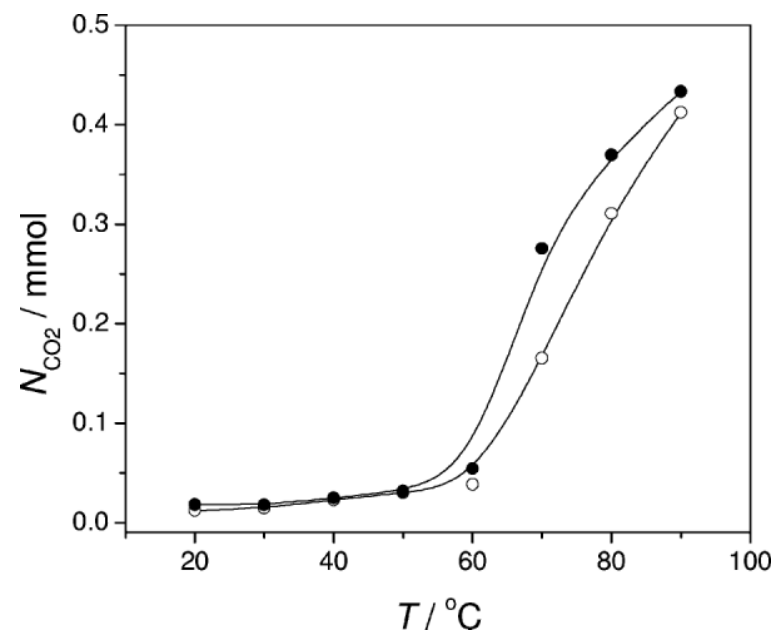

Figure 5. The production of $\mathrm{CO}_{2}$ under different reaction temperatures: $(\bigcirc)$, ferroin-catalyzed system and $(\bigcirc)$, ferroin-free system

The above results strongly suggest the existence of carbon dioxide gas production in this system.

As the onset of observable bubbles occurred at $60^{\circ} \mathrm{C}$, the bromate-CHD reaction was repeated at that temperature. ${ }^{1} \mathrm{H}$ NMR spectral analysis of the diethyl ether extract for both the catalyzed and catalyzed mixtures at $90 \mathrm{~min}$ after the start of the reaction showed the presence of a trace amount of dibromoacetic acid and substantial amounts of 5-dibromomethylene-2 $(5 \mathrm{H})$-furanone (1) and (E)-5,5,5-tribromo-4-oxo-2-pentenoic acid (2), although in the latter case in more modest amounts than at $90^{\circ} \mathrm{C}$ (approximately equimolar with benzoquinone). In addition, 1,4-benzoquinone, 2-bromo-1,4-benzoquinone, and 2,5-dibromo-1,4-benzoquinone were present in significant amounts. Finally, ${ }^{1} \mathrm{H}$ NMR resonances at $\delta 6.72(\mathrm{~s}, 2 \mathrm{H})$ and $4.80(\mathrm{~s}, 2 \mathrm{H})$ indicated the presence of 5,6-dibromo-2-cyclohexene-1,4-dione, a material that is likely an intermediate in the conversion of 1,4-benzoquinone to 2-bromo-1,4-benzoquinone, via elimination of $\mathrm{HBr}$.
To decipher the source of the furanone and (E)-5,5,5tribromo-4-oxo-2-pentenoic acid production, we examined the acidic bromate-benzoquinone solution at $90^{\circ} \mathrm{C}$. After $90 \mathrm{~min}$, the extract solution yielded a ${ }^{1} \mathrm{H}$-NMR spectrum containing most of the same species (specifically dibromoacetic acid, 5-dibromomethylene-2(5H)-furanone, and (E)-5,5,5-tribromo-4oxo-2-pentenoic acid) as the 1,4-CHD reactions, albeit in different ratios. Consequently it is most likely that these materials are occurring by oxidation, hydrolysis and bromination reactions once benzoquinone is formed, rather than from 1,4-CHD directly.

Plausible schemes for the formation of the compounds are indicated below (Schemes 1 and 2), with the caveat that the timing of some of the bromination, oxidation, and decarboxylation steps could reasonably be reversed. Nevertheless, given the significant amounts of 5,6-dibromo-2-cyclohexene-1,4-dione at $60^{\circ} \mathrm{C}$, we have chosen brominated benzoquinones as the starting points for the ring opening processes. Baeyer-Villiger type oxidation of bromobenzoquinone is capable of forming lactone $\mathbf{3}$, which would be susceptible in aqueous acid to hydrolysis to form carboxylic acid-containing keto-aldehyde 4 . It may also be possible that this overall transformation of benzoquinone to $\mathbf{4}$ is accomplished via a Lieben haloform reaction, as they are known to be initiated by both silver bromate and $\mathrm{NaOBr}_{i}^{[23,24]}$ we consider this less likely due to the strongly acidic conditions in the current case. Following aldehyde oxidation of $\mathbf{4}$ to the $\beta$-keto acid function ((Z)-5), acid induced hemi-acetal formation (6), and dehydration would give (7), which has been proposed previously by our group to undergo a Hunsdiecker-type decarboxylative bromination ${ }^{[25-28]}$ to give the furanone (1). As a possible alternative, ((Z)-5) could undergo $\alpha$-carbonyl bromination and decarboxylation to give ((Z)-8), which after cyclization of the 1,4-dicarbonyl function would also afford 1. With respect to (E)-5,5,5-tribromo-4-oxo-2-pentenoic acid (2), ((Z)-5) would be expected to undergo acid catalyzed alkene isomerization to give ((E)-5), prior to $\alpha$-carbonyl bromination and decarboxylation (or Hunsdiecker reaction) to give ((E)-8), which readily could undergo further acid catalyzed ketone $\alpha$-bromination to give (2). It is additionally plausible that the furanone may

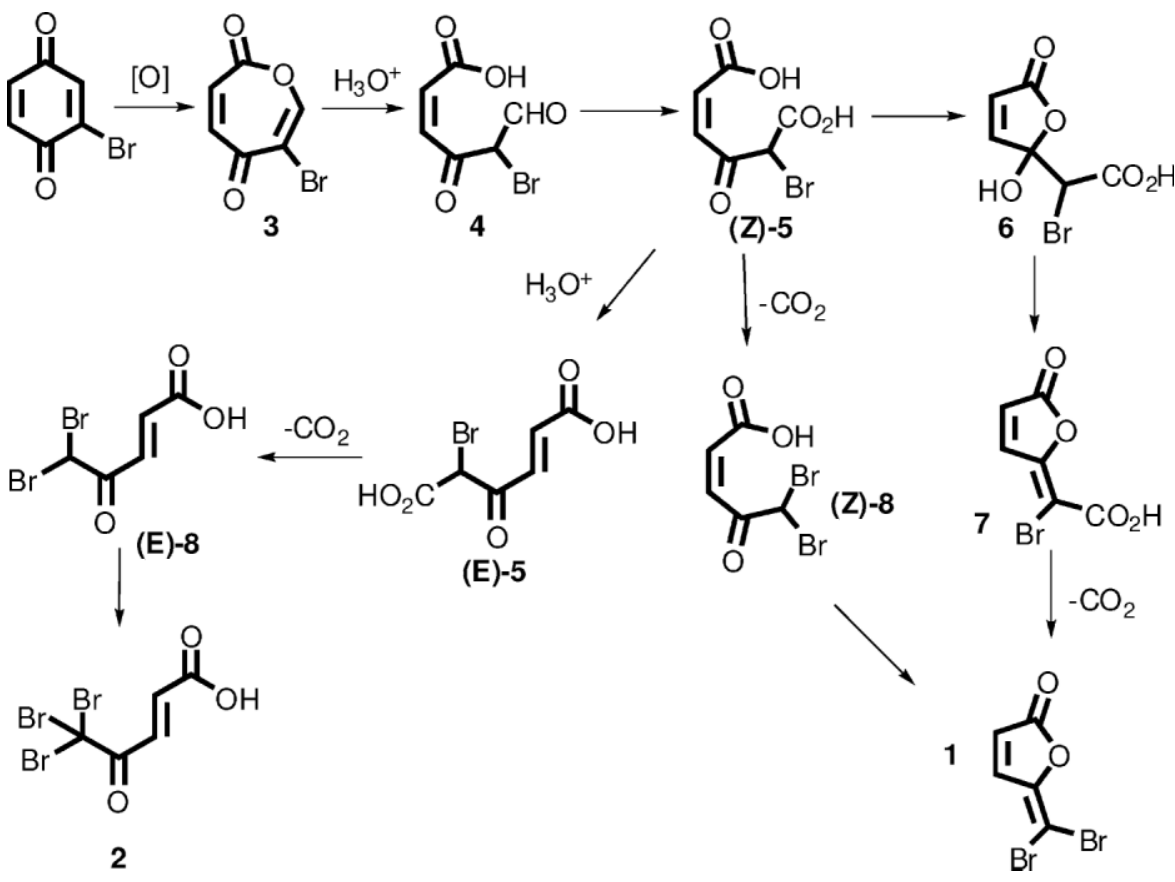

Scheme 1. Proposed formation of $\mathbf{1}$ and $\mathbf{2}$ 


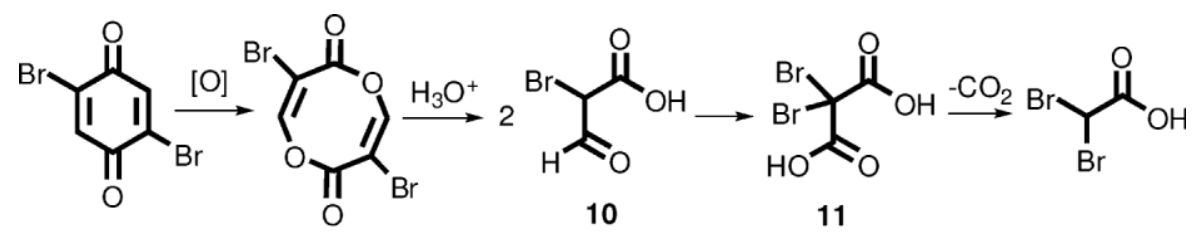

9

Scheme 2. Proposed formation of dibromoacetic acid

undergo hydrolysis and alkene isomerization to give ((E)-8). As a final comment, compound $((\mathbf{E})-\mathbf{8})$ is unreported, but one of the minor components in the $90{ }^{\circ} \mathrm{C}$ reaction mixture, giving ${ }^{1} \mathrm{H}$ NMR resonances at $\delta 7.75(\mathrm{~d}, J=15.5 \mathrm{~Hz}, 1 \mathrm{H}), 7.02(\mathrm{~d}, J=15.5 \mathrm{~Hz}, 1 \mathrm{H})$, and $5.91(\mathrm{~s}, 1 \mathrm{H})$, is consistent with this compound.

The most plausible mechanism for dibromoacetic acid formation also initiates with Baeyer-Villiger oxidations, but of 2,5-dibromobenzoquinone, and on both ketone carbonyls, affording eight-membered ring compound 9. Hydrolysis of the enol ester functions would then afford two molecules of brominated $\beta$-oxo carboxylic acid 10. Further bromination $\alpha$ to the two carbonyls and oxidation of the aldehyde would give dibromomalonic acid 11, which would be readily susceptible to decarboxylation to give dibromoacetic acid.

\section{CONCLUSIONS}

Ring-opening products 5-dibromomethylene-2(5H)-furanone, dibromoacetic acid, and (E)-5,5,5-tribromo-4-oxo-2-pentenoic acid have been detected in the bromate-1,4-cyclohexanedione reaction with or without the presence of metal catalyst. This serves as a caution to the general belief that six-membered ring systems are infinitely stable in acidic bromate solution and thus suitable under all conditions for developing bubble free chemical oscillators. Our parallel experiments suggest that the ring-opening process is due to the oxidation of benzoquinone by bromate after bromination; as a result, this process is not likely involved in the nonlinear feedback loop. The amount of $\mathrm{CO}_{2}$ produced increases with reaction temperature, and rapidly so above $60^{\circ} \mathrm{C}$. Nevertheless, the relatively greater robustness of the 1,4-CHD-BZ reactions can now be put in its proper context. Whereas the malonic acid-BZ reaction produces gases even under mild reaction conditions, and the pyrocatechol- $\mathrm{BZ}$ reaction requires high bromate and substrate concentrations but ambient temperature, in the 1,4-CHD-BZ reaction a significant amount of gas production can only be obtained when the reactant concentration and reaction temperature are high. This requirement for relatively vigourous reaction conditions may explain why no gas bubble formation has been reported in the general bromate-CHD reaction.

\section{Acknowledgements}

This work was supported through the Natural Sciences and Engineering Research Council of Canada (NSERC) and Canada Foundation for Innovation (CFI).

\section{REFERENCES}

[1] E. Körös, M. Orbán, Nature 1978, 273, 371-372.

[2] M. Orbán, E. Körös, J. Phys. Chem. 1978, 82, 1672-1674.

[3] V. J. Farage, D. Janjic, Chem. Phys. Lett. 1982, 88, 301-304.

[4] K. Kurin-Csörgei, A. M. Zhabotinsky, M. Orbán, I. R. Epstein, J. Phys. Chem. A 1997, 101, 6827-6829.

[5] L. Adamčíková, Z. Farbulová, P. Ševčík, New J. Chem. 2001, 25, 487-490.

[6] K. Kurin-Csörgei, I. Szalai, E. Körös, React. Kinet. Catal. Lett. 1995, 54, 217-224.

[7] D. S. Huh, H. S. Kim, J. K. Kang, Y. J. Kim, D. H. Kim, S. H. Park, K. Yadav, J. Wang, Chem. Phys. Lett. 2003, 378, 78-84.

[8] C. T. Hamik, N. Manz, O. Steinbock, J. Phys. Chem. A 2001, 105, 6144-6153.

[9] I. Szalai, E. Körös, J. Phys. Chem. A 1998, 102, 6892-6897.

[10] I. Szalai, K. Kurin-Csörgei, I. R. Epstein, M. Orbán, J. Phys. Chem. A 2003, 107, 10074-10081.

[11] J. Wang, K. Yadav, B. Zhao, Q. Gao, D. Huh, J. Chem. Phys. 2004, 121, 10138-10144.

[12] A. F. Taylor, M. R. Tinsley, F. Wang, Z. Huang, K. Showalter, Science 2009, 323, 614-617.

[13] D. S. Huh, S. J. Choe, M. S. Kim, React. Kinet. Catal. Lett. 2001, 74, 11-22.

[14] N. Manz, S. C. Müller, O. Steinbock, J. Phys. Chem. A 2000, 104, 5895-5897.

[15] C. T. Hamik, O. Steinbock, Phys. Rev. E 2002, 65, 1-7.

[16] A. Goldbeter, Biochemical Oscillations and Cellular Rhythms, Cambridge University Press, Cambridge, 1996.

[17] R. Straube, D. Flockerzi, S. C. Müller, M. J. B. Hauser, Phys. Rev. E. 2005, $72,1-12$.

[18] A. Sensse, M. J. B. Hauser, M. Eiswirth, J. Chem. Phys. 2006, 125, $1-12$

[19] F. X. Witkowski, L. J. Leon, P. A. Penkoske, W. R. Giles, M. L. Spanol, W. L. Ditto, A. T. Winfree, Nature 1998, 392, 78-82.

[20] I. R. Epstein, J. A. Pojman, An Introduction to Nonlinear Chemical Dynamics, Oxford University Press, New York, 1998.

[21] T. Bánsági, M. Leda, M. Toiya, A. M. Zhabotinsky, I. R. Epstein, J. Phys. Chem. A 2009, 113, 5644-5648.

[22] M. Harati, J. R. Green, B. F. T. Cooper, J. Wang, J. Phys. Chem. A 2009, $113,6548-6551$.

[23] H. Loghmani-Khouzani, B. Osmailowski, R. Gawinecki, E. Kolehmainen, R. W. Harrington, W. Clegg, J. Iran. Chem. Soc. 2006, 3, 173-179

[24] J. Aguilera, R. Gutiérrez-Abad, À. Mor, A. G. Moglioni, G. W. Moltrasio, R. M. Ortuño, Tetrahedron Asymmetry 2008, 19, 2864-2869.

[25] M.-A. Bazin, L. El Kihel, J.-C. Lancelot, S. Rault, Tetrahedron Lett. 2007, 48, 4347-4351

[26] C. Kuang, Q. Yang, H. Senboku, M. Tokuda, Synthesis 2005, 1319-1325

[27] R. M. Moriarty, J. Org. Chem. 2005, 70, 2893-2903.

[28] For a review on carboxylic acid decarboxylations, see: R. A. Sheldon, J. K. Kochi, Org. React. 1972, 19, 279-421. 